Fecha de recepción: febrero 2020 Fecha de aceptación: marzo 2020 Versión final: abril 2020

\section{Un análisis de los videojuegos como agenciamientos}

Luis Rossi ${ }^{(1)}$

Resumen: En los últimos años diversos estudios han abordado los límites y posibilidades de los videojuegos como expresión cabal de la industria cultural globalizada pero también como frontera resistente al capitalismo. No obstante, estas conceptualizaciones suelen omitir los rasgos fundamentales de los videojuegos como dispositivos o agenciamientos de las sociedades contemporáneas así como sus relaciones con los modos de subjetivación forjados en el engagement (ritornelo). Nuestra propuesta buscará recuperar los elementos que permiten pensar a los videojuegos como condensación de regímenes de signos (imágenes) y materialidades identificando las líneas (moleculares, molares y abstractas) que componen (re/territorializan) a los agenciamientos de juego digital (semióticas intensivas de la espacialidad, de las mecánicas y de la gameplay), así como sus posibles líneas de fuga (desterritorializaciones). Asimismo, si el modelo analítico encuentra sus fundamentos teóricos en el posestructuralismo francés, la investigación se apoyará en los principales aportes de la ludología aplicada. Por ello nuestro escrito estará basado en recorridos empíricos (grillas comparativas) sobre un corpus de 45 videojuegos producidos entre 2010 y 2016 en las Global Game Jams de la ciudad de Santa Fe.

Palabras clave: regímenes de signos - materialidades - agenciamientos de juego - Global Game Jams - engagement - ludología aplicada.

[Resúmenes en inglés y portugués en las páginas 141-142]

(1) Doctor en Ciencias Sociales por la Universidad Nacional de Entre Ríos (FCEdu-UNER) y becario postdoctoral del Consejo Nacional de Investigaciones Científicas y Técnicas (CONICET).

\title{
Introducción
}

Los videojuegos han sido problematizados como formas culturales paradigmáticas del capitalismo del siglo XXI en tanto expresan transformaciones en las relaciones de poder, en las formaciones de saber, en los regímenes de signos y en los linajes socio-técnicos (Cremin, 2016; Galloway, 2006; Dyer-Witheford, 2009; Apperley, 2011). Continuando esas ideas y 
profundizando sus niveles analíticos, nosotros proponemos tomar el modelo de juegos anticipado por Gilles Deleuze (2008) (y desplegado junto con Félix Guattari, 1997), para pensar a los videojuegos como agenciamientos centrales en nuestras sociedades. La importancia de estas componendas (o dispositivos) se cifra en su capacidad para disponer manojos de líneas-flujos en vías de estratificación que reúnen semióticas y materialidades produciendo procesos de engagement (o reterritorializaciones artificiales) que están en el corazón de los modos de subjetivación contemporáneos, en tanto los juegos encierran un cierto poder de acción sobre las acciones de jugadoras/es y desarrolladoras/es (Rossi, 2018a, 2019).

Para el dúo filosófico francés los agenciamientos de juego cuentan con tres líneas principales. En primer lugar, una línea compuesta de movimientos sensibles y curvos que implican segmentos flexibles como gestos y posturas (pero que no son asignables a un sujeto individuado a priori). Se trata de una dimensión molecular de las componendas donde tienen asiento semióticas intensivas, de la corporeidad o lúdicas que son centrales para explicar el engagement. Para Deleuze y Guattari los agenciamientos massmediáticos y los de la informática también desencadenan estos regímenes conocidos como pequeños ritmos sociales (ritornelos). De allí que se puedan extender sus conceptualizaciones a los videojuegos como formas de coagular dinamismos espacio-temporales (I, II, III). Asimismo, siguiendo a G. Simondon, para nosotros esas semióticas intensivas (desencadenantes de afectos y perceptos) pueden ser pensadas como imágenes ${ }^{1}$ (Rossi, 2018b) en tanto multiplicidades compuestas de configuraciones espaciales, mecánicas y dinámicas que conforman lo que la literatura ludológica ha denominado gameplay (pensamiento imagético en jugadoras/ es y desarrolladoras/es).

En segundo lugar, el agenciamiento de juego guarda una línea de segmentaridad rígida que se corresponde con las narraciones de la actividad lúdica. Esta dimensión molar expresa relaciones binarias y biunívocas entre planos representacionales, por lo que supone un proceso consciente de identificación (sujeción) de las/os jugadoras/es con agentes, relatos, eventos, etc. -como lo intuye la narratología-. Por supuesto, esta característica se relaciona con la anterior, pues las líneas moleculares pueden tener un vector representacional o segmentarizable.

Por último, para Deleuze y Guattari en todo juego hay una línea abstracta que no es ni figurativa, ni simbólica y que se constituye por un movimiento que comporta singularidades, posiciones de detención y puras velocidades. Es la línea diagramática de territorialización y desterritorialización de las componendas de juego donde están contenidas materias no formadas y funciones no finalizadas (máquinas abstractas). Si esta línea se expresa en los procesos informacionales derivados de las reglas, estados y procedimientos que postulan a los juegos como procesadores de información, también encierra su pragmática política, pues pone en acto la conexión de los videojuegos con otras formas culturales que contienen signos a-significantes (como régimen semiótico del capitalismo contemporáneo que opera desde las materialidades).

La literatura especializada en videojuegos ha abordado estas tres líneas (segmentadas -molares-, segmentarizables -moleculares- y abstractas -diagramáticas-) a partir de múltiples modelos analíticos en acercamientos empíricos. Inspirados en estos intentos hemos reparado en tres decisiones metodológicas. En primer lugar, conformamos un corpus que, a 
contramano de la constante atención en los juegos consagrados de la industria cultural, se detendrá en los videojuegos desarrollados entre 2010 y 2016 en el marco de las jornadas Global Game Jams ${ }^{2}$ (GGJ) en sus sedes de la ciudad de Santa Fe (Rossi, 2019) ${ }^{3}$. Para ello construimos grillas comparativas ${ }^{4}$ que nos permitieron tanto atravesar este corpus lúdico indie profundizando en los esquemas de desarrollo presentes en el cognitariado como comprender la potencialidad de las líneas de fuga (Pedercini, 2014). En segundo lugar, partiremos de las semióticas intensivas de los videojuegos, pues hemos observado que en los grupos de desarrolladoras/es el concepto de juego comienza a partir de discusiones sobre la construcción de la gameplay. Permítasenos pensar entonces que el juego nace de imágenes y no de representaciones molares. Por supuesto, con esto no intentamos negar las complejidades narrativas y los mundos posibles encarnados el tratamiento temático, sino subrayar que el engagement del agenciamiento videojuegos es construido a partir de sus dinamismos espacio-temporales que conforman líneas moleculares en tanto median entre segmentos molares (I) y semióticas abstractas (III). Por último, dado que los videojuegos son mixtos complejos, el principio analítico que adoptamos es el de la ludología aplicada que permite comprender cómo se juega en tanto función de las distintas opciones de diseño que encarnan reglas en elementos y componentes concretos (Järvinen, 2008; Eskelinen, 2012).

Así, en los apartados subsiguientes recorremos los procesos de territorialización de los videojuegos como agenciamientos partiendo de sus líneas moleculares y molares (I, II) y abordando sus conexiones con líneas abstractas (III). Con ello daremos cuenta de la importancia de estas componendas para nuestras formaciones sociales en tanto se coagulan articulando poder, saber y subjetivación. Ello nos permitirá pensar algunas líneas de fuga o desterritorializaciones que resisten a través de creaciones en la axiomática capitalista (IV).

\section{De la molecularidad espacial a las dimensiones molares}

Hemos sostenido que el agenciamiento videojuegos está atravesado por líneas abstractas, moleculares y molares. Entre estas últimas dos se abre una arquitectura de los espacios a través de semióticas intensivas que movilizan el acto de territorialización (o ritornelo). Por supuesto, tanto los clásicos ludológicos que comprendían a los juegos como medioambientes, mundos, círculos, áreas, campos, etc. como el reciente giro espacial y material (Newman, 2004; Papadopoulus, 2011; Walz, 2010; Shinkle, 2005; Meldgaard, 2011) no dudarán en ver al espacio como decisivo para el game design. Así, es posible afirmar que los videojuegos se inscriben permanentemente en imágenes espaciales que se combinan con la percepción de lo moviente (mecánicas) para conformar una tecnología que trabaja sobre distancias operatorias y sociales (Rossi, 2018b). De hecho, estas semióticas intensivas de la espacialidad están ligadas a procesos constructivos históricamente condicionados (Dovey y Kennedy, 2006; Rossi, 2018c) y son identificables en las discusiones de los grupos de la GGJ que versan sobre topologías variables (atravesando géneros y modalidades). Según refiere Nitsche (2008) una de las vías de estas construcciones espaciales pasa por las cámaras virtuales y los puntos de vista (fijos o móviles) en tanto, como diría V. Flusser, 
técnicas imagéticas cerodimensionales que afectan la construcción de los planos de distancia-proximidad (fungiendo como filtros narrativos). De toda la variedad de construcciones posibles, la mayoría de los juegos que analizamos contaban con cámaras en tercera persona con visión sobre el avatar $(3,6,13,14,16,18,32$ y 39), algunos implementaban isometría $(7,9)$ y abundaban los puntos de vistas fijos $(1,4,5,15,17,21,23,24,25,28,29$, $30,31,34,35,36,40,41,42,43$ y 45$)$.

Al mismo tiempo, bajo la herencia de los arcades, los juegos de las GGJ recurren a técnicas como el scrolling que permite continuar la acción y ampliar el movimiento en el fuera de cuadro del game world $(2,5,14,19,21,23,25,28,29,31,32,34,35,36,39,42$ y 45). De allí que se orienten hacia temáticas de exploración, aventura y conquista. Esas configuraciones se diferencian de los juegos de pantalla única donde las/os jugadoras/es combaten en espacios que contienen posibles ataques $(4,6,13)$. Asimismo, si bien los escenarios retrogaming se destacan en las GGJ, los mundos 3D de las cámaras FPS han comenzado a aparecer en los diseños indie gracias a los game engines (26, 27, 38 y 44).

Estas técnicas de construcción espacial son fundamentales para el level design como proceso arquitectónico de mapeo que dispone magnitudes intensivas y permite la percepción de la distancia. Asimismo, más allá de esas técnicas, las semióticas intensivas también están constituidas por configuraciones espaciales. En primer lugar, existen estructuras laberínticas (Gazzard, 2009) que extienden la gameplay retrasando y singularizando las partidas en trayectorias emergentes $(7,16,18,19,24,26,27,30,32,35,37,39,44)$. Además de los laberintos son frecuentes las arenas que proveen un entorno hostil que propicia la supremacía territorial y donde, como señala Papadopoulos (2011), la/el jugador/a está en el medioambiente pero no pertenece a él -por tanto su integración se transforma en lucha $(1,4,5,6,10,13,14,17,20,21,23,31,32,34,35,36,37,40,41,42,43,45)$. A estas configuraciones espaciales se le suman rutas y pistas que son circuitos de acción en altas velocidades $(2,3,12,11,17,28,29,35,37)$.

No obstante, los videojuegos en tanto ritornelos son también actos territoriales que, más allá de las configuraciones visuales, construyen su engagement a través de ambientes o paisajes sonoros. Para Collins (2013) esta sonoridad (músicas, efectos, discursos, etc.) les permite exceder la bidimensionalidad de la pantalla. De hecho, de los 45 juegos analizados sólo una quinta parte no contiene audios pero, de acuerdo con sus desarrolladoras/es, ello se debe a los tiempos acelerados de la producción en las jams. Volveremos sobre la sonoridad a partir de las mecánicas (II).

Ahora bien, como dijimos, entre las líneas molares y moleculares hay un tránsito permanente, por ello no es extraño que la construcción del espacio haya sido ligada a una forma particular de narrativa como domino de la geografía de mundos imaginarios. Así, en los grupos de la GGJ, es fácil constatar que las narraciones e historias emergen de mapas ( 1,5 , $18,19,27,30,34,35,36,40,41,42,43$ y 44$)$. No obstante, si bien una corriente importante de teóricos de los videojuegos ha ligado la noción de engagement con la de inmersión o participación en una historia o drama, nosotros seguimos a Järvinen (2008) y J. Juul para quienes los sistemas de juego sólo metafóricamente pueden ser comprendidos en base a retóricas apoyadas en la tematización. Los relatos son formas de distribuir información sobre reglas, metas, conflictos, agentes, etc. al tiempo que el tema puede ser utilizado para 
disfrazar y reciclar elementos o mecánicas similares. En las GGJ los géneros temáticos más recurrentes para estas operaciones son los de ciencia ficción $(1,5,10,20,21,36)$, fantasía y aventuras $(6,14,17,18,19,23,28,34,35,39,42)$, suspenso y horror $(1,7,9,19,26,27$, $30,32,34,40)$ y comedia $(2,25,40,43,44$ y 45$)$.

Además del tema, los game worlds suponen tres elementos: agentes, eventos y objetos (Järvinen, 2008). Mientras a los dos últimos los veremos en relación a las mecánicas, ciertos agentes o avatars en los juegos de las GGJ están relacionados con el retrogaming y responden a la abstracción de la funcionalidad sin caracterización $(2,4,13,16,20,21,23,24$, $29,31,38,40)$. Sin embargo, también existen casos donde los personajes se identifican rápidamente con elementos de un capitalismo techno-chute en los marcos temáticos que la industria cultural ha popularizado $(1,5,6,8,14,17,18,19,25,26,27,28,30,32,34,35$, $36,39,41$ y 42 ).

Tanto en la tematización como en los agentes se hacen visibles elementos de sujeción social por sus componentes representacionales e ideológicos de orden molar (desiertos de tóner se gastan para indicar que ciertos personajes representan la violencia militar, la autopercepción empresarial, etc.). Sin embargo, se podría decir con Galloway (2006) que: "cuanto más intentamos determinar la crítica ideológica, más se observa que tal crítica está minada por la existencia de algo muy diferente a la ideología: el código informático. Así, donde la crítica ideológica tiene éxito, falla" (p.102). Pues, los videojuegos como agenciamientos siempre están en contacto con las semióticas diagramáticas o a-significantes de la información en las formaciones sociales del control (III) (Rossi, 2018a).

\section{Semióticas intensivas: de las mecánicas a la duración}

Desde antaño los juegos han sido definidos como conjuntos o sistemas de reglas en tanto guías prescriptas de acción o emergentes conductuales. Por ello su construcción y reutilización se puede pensar como el núcleo mismo del diseño (Eskelinen, 2012). No obstante, hay que señalar que los desarrolladores de las GGJ no comparten reglas a secas, sino imágenes intermediarias (transductivas) que son multiplicidades de elementos heterogéneos en tanto líneas moleculares de las grandes ludotecas que conocen.

Al mismo tiempo las reglas engendran dos aspectos fundamentales que completan los eventos del juego. Por un lado, los procedimientos de los estados variables que responden a las acciones del jugador y, por otro, las mecánicas y dinámicas del juego como actos. Así, los procedimientos pueden ser definidos como el conjunto de reglas ejecutadas por agentes maquínicos automatizables y lógicos que van desde tableros a software y que proveen a las/ os jugadoras/es de un feedback informacional (en una racionalización constituida históricamente, Rossi, 2018c). En otros términos, son operaciones de las formas de contenido que estratifican las formas de expresión y que definen a los sistemas de juego, en palabras de F. Kittler, como medios de almacenamiento, procesamiento y transmisión de información. El otro lado de los procedimientos son las mecánicas u operaciones para influir sobre los estados del juego. Se trata de verdaderas imágenes o multiplicidades de elementos y comportamientos que tienen la capacidad de asignar relaciones causales entre elementos 
y estados del juego, pues influyen en estos últimos. De acuerdo a Järvinen (2008) y D. Parlett, las mecánicas pueden ser analizadas globalmente a través de una suerte de ingeniería inversa (no siempre libre de ambigüedad). Evidentemente, los videojuegos pueden componerse de diferentes mecánicas durante la gameplay, aunque es posible reconocer un conjunto central de las mismas que soportan su invención. Por ello, en nuestras grillas de análisis sobre los 45 juegos de las GGJ, hemos identificado las siguientes mecánicas como las más frecuentes: mover (agentes o elementos) $(1,4,6,16,17,19,28,31,32,34$, $35,37,39,43)$; tomar y recolectar $(1,14,18,19,27,28,35,38,39,40,42,43,44,45)$; evadir, esquivar y evitar $(1,15,17,18,19,21,29,31,36,39,43,45)$; ordenar, componer y combinar $(2,3,7,11,20,22,24,25,26,35,37,44)$; apuntar y disparar $(4,5,6,7,9,10,13,21,22,23$, 41); saltar $(1,15,17,29,30,35,40,42,45)$, atacar y defender $(6,5,13,23,37,39,42,45)$; acelerar y desacelerar $(15,18,21,24,40,42,45)$; $y$ correr $(8,9,12,25,26,29,36)$. No es extraño que estos grandes grupos de mecánicas definan lo que las/os desarrolladoras/es llaman "plataformeros" y "puzzles" evocando ludotecas arcades. Al mismo tiempo, todas ellas se combinan con las configuraciones espaciales que destacamos más arriba (laberintos, arenas y pistas) e implican una compenetración de las percepciones de las formas y de lo moviente. En otro nivel se pueden identificar mecánicas infrecuentes que indican otras especies de gameplays como, por ejemplo, maniobrar $(5,18,21,30,37)$, expresar y escribir $(8,33,37,38)$; navegar y explorar $(19,26,27)$; operar y ejecutar $(2,17,26)$; controlar $(22$, 26) y conversar $(14,27)$. Entre las más extrañas encontramos mecánicas de distribuir (20), negociar (25); moverse en grupo (28), situar o clasificar (26) y potenciar(se) (15). Si bien las mecánicas más frecuentes, pregnantes en la industria cultural, se superponen con éstas últimas, las mismas extienden las duraciones de la gameplay y ello, en ciertas ocasiones, ayuda a romper las estratificaciones de la velocidad de los juegos (IV).

Por otra parte, estas mecánicas encuentran en la sonoridad la membrana que entreteje el mundo del juego y el de las/os jugadoras/es construyendo el engagement (ritornelo) a partir de lo que Collins (2013) denomina síntesis cinético-sónica. Concretamente, de los 36 juegos que incluían audio sólo tres contenían sonidos no dinámicos donde la sonoridad se restringía a la música en loop $(25,34$ y 45$)$, mientras que los demás integraban audios dinámicos. Los más frecuentes en las GGJ son los audios interactivos que reaccionan a las mecánicas del jugador $(4,5,6,7,8,10,13,17,18,19,20,21,22,23,24,27,28,29,34,35$, $36,37,38,39,40,41,42,43$ y 44$)$ y, en menor medida, encontramos audios adaptativos que reaccionan a cambios de estados $(1,2,4,28,35$ y 37$)$. Esta sonoridad es una pieza clave de las reterritorializaciones artificiales pues ilustra la colaboración entre estados y mecánicas con formas de sincronización o percepción de la duración de los juegos. De hecho, el término gameplay asocia la experiencia lúdica a dinámicas temporales emergentes del loop cibernético en el cual las/os jugadoras/es se vuelven inseparables de la duración del juego y se sincronizan con los estados variables (Dovey, 2006). 


\section{Líneas abstractas: de la gameplay a las semióticas a-significantes}

Como anticipamos, la relación entre mecánicas, elementos, procedimientos y reglas da nacimiento a la gameplay en tanto dinámica temporal que puede ser analizada a través de los estados de juego. Así, la gameplay implica que los juegos sean verdaderas máquinas o sistemas dinámicos de estados reconocibles. De allí que los estados sean definibles, como quiere G. Scheines, como puntos de referencia temporales; campos de fuerzas que crean ritmos automatizables y variables. Siguiendo a P. Fraisse podemos decir que los videojuegos como agenciamientos tienden a conformar una regularidad (no métrica) de cambios que permiten la percepción de la sucesión. Entre estos estados hay intervalos que duran y es justamente esta duración la que posibilita fenómenos de sincronización que se diferencian de la mera reacción.

Así, los estados cambiantes de los juegos como materialización de la duración de la gameplay son semióticas intensivas que tienen su concretización en el level design y que son omnipresentes en el pensamiento de las/los desarrolladoras/es de las GGJ. Las cuatro configuraciones temporales de estados que hemos encontrado en las GGJ responden a construcciones socio-históricas del maquinismo (Rossi, 2018c) y son: las barras de energías o vidas y contadores de puntajes $(1,2,4,5,6,7,12,13,18,20,21,23,22,26,27,39$, 41, 43 y 45); los marcadores temporales como cronómetros, rutinas de la IA y la aparición secuencial y diferencial de obstáculos $(22,30,38,42$, etc.); la concatenación de niveles $(3,5,17,18,19,20,22,24,28,30,32,34,35,36,37$ y 40) y, por último, los conocidos indicadores de finalización de partidas. Son menos frecuentes las imágenes temporales de estados que se diseñan como variaciones de los espacios (11 y 12), las cutscenes (14 y 25) o cambios en la composición del avatar (18 y 31). Todas estas imágenes afectan tanto el núcleo de los desarrollos como los ritmos de sincronización de la gameplay y forjan, como quiere Dovey, un feedback loop con las/os jugadoras/es que es la base de la reterritorialización artificial como control de las intensidades y velocidades (asservissement machinique, Rossi, 2018a, 2019).

Asimismo, los estados están ligados a las reglas sobre metas parciales y globales que afectan la duración de la gameplay. Así, en los juegos de las GGJ las metas, por lo general, se construyen de acuerdo a los estados finales, por ello las más asiduas -sin contar la omnipresente recolección de elementos- pasan por completar la gameplay atravesando niveles $(1,3,5,11,15,16,17,18,19,26,27,28,30,31,34,35,36,37,39,40$ y 45); derrotar al oponente o al sistema $(7,9,10,12,13,24,26,38,41,42$ y 43$)$ y acumular puntaje $(2,5$, $6,20,21,23,29$ y 37$)$. No obstante, hay juegos en los que las metas han sido redefinidas para combinar elementos ( 42 y 44), completar tareas específicas (37 y 39), memorizar y ejecutar patrones correctos ( 25 y 33); o, simplemente, escribir la palabra exacta (8).

Dado que el sistema de juego se apoya en un conjunto de procedimientos y estados que procesan, almacenan y transmiten información, para Järvinen se puede pensar a los videojuegos como simulaciones, en la medida en que se vuelven modelos operativos de otros sistemas. Sin embargo, esta noción de simulación también puede comprenderse a través de Friedman (2002) quien señalaba que en los juegos de simulación de vistas fijas (e.g. Kriegsspiele) las computadoras reorganizan el pensamiento y la percepción vehiculizando 
una colaboración profunda entre jugadores e IA y logrando una internalización de la lógica algorítmica. Para Friedman esas dinámicas generaban un continuo feedback loop en el cual la línea que demarca el fin de la conciencia y el comienzo del mundo computacional se evaporaba. Newman (2004) y Dovey (2006), con buen tino, sostienen que estas características pueden extenderse a todos los juegos en los que el código presenta mundos renderizados y estados variables.

En una línea similar, para Bogost (2006), los videojuegos son artefactos construidos a partir de unidades de sentido que configuran medioambientes digitales caracterizados por la ejecución de reglas. Esas unidades pertenecen a las prácticas del paradigma de programación orientado a objetos (POO) que encapsulan estados, clases, eventos, comportamientos, métodos, librerías y modelos (assets) cifrando una suerte de capital cognitivo reutilizable y conectando el desarrollo con game engines y middleware. Estos game engines son sistemas dinámicos que controlan el mundo de juego a través de elementos, física, IA, al tiempo que generan plataformas de renderización audiovisual e interfaces de hardware. Así, los middleware, populares entre los desarrollos indie por su economía, estandarizan los procedimientos algorítmicos que conforman la arquitectura de los juegos, pero exceden los géneros regulando las formas y sustancias de expresión de los videojuegos (en el marco del trabajo digital, Rossi, 2019).

Evidentemente los middleware responden a un momento histórico de la producción de videojuegos donde hay una tendencia hacia la estandarización. De los desarrollos de las GGJ analizados, 17 se realizaron con game engines, mientras que 15 fueron diseñados con tecnología flash y 13 con entornos y compiladores. Sin embargo, cabe destacar que, a partir de 2014, la gran mayoría de los juegos analizados se realizaron con game engines (Unity, GameMaker y Construct 2). Este tándem entre middleware, POO y simulación evidencia que los videojuegos como agenciamientos están atravesados por líneas abstractas compuestas de semióticas maquínicas o a-significantes que conjugan procesos informacionales actuando directamente sobre los flujos materiales. De hecho, la fuerza del Capitalismo Mundial Integrado yace en la explotación de esas máquinas que regulan las velocidades de las semióticas intensivas (Rossi, 2018a). Sin embargo, esta conjugación también guarda posibilidades inusitadas a las que sólo tienen acceso las/os desarrolladoras/es.

\section{Desterritorializaciones, líneas de fuga}

Hemos señalado las tendencias al interior del agenciamiento videojuegos que van de lo molecular a lo molar teniendo como eje a las configuraciones espaciales omnipresentes en las jams (I). Luego advertimos que el movimiento de expansión de las semióticas intensivas se presenta también en las mecánicas y en la gameplay (en tanto duración) para gestar reterritorializaciones artificiales o engagement (II). Por último, sostuvimos que los cambios en los estados postulan a los videojuegos como sistemas de información, con ello dimos un paso de lo molecular a lo abstracto (semióticas a-significantes; III). Estas semióticas informacionales constituyen el núcleo dinámico de la modulación de las velocidades en las formaciones sociales de control. 
Sin embargo, no se puede conjugar una máquina deseante tan potente como el juego con la producción social sin que se produzcan fugas. Por ello diversos autores señalan que si los videojuegos responden al capitalismo cognitivo también configuran máximos de creación y de desterritorialización que pueden anticipar prácticas lúdicas de la Multitudo contra-juegos.

No obstante, esas rupturas nunca son homogéneas y tienen casos diferentes que se despliegan en distintos niveles micropolíticos. Existen fugas estructuradas sobre las líneas molares que se presentan desde los procesos mismos de invención cuando las/os desarrolladoras/es tratan de quebrar las máquinas binarias de la industria cultural. Así, no son extraños los juegos que, como los serious games, evitan situaciones violentas, ensayan identidades de género diversas o demuestran preocupaciones ecológicas (6). En el mismo sentido hay proyectos más ambiguos $(7,9)$ que intentan alterar las temáticas y disponer al jugador en posiciones desacostumbradas. Al mismo tiempo, siguiendo a Berardi y a Stiegler, podría decirse que inventar ludotecas en las GGJ es ya una forma de luchar contra la sociedad de consumo controlado (e.g. open source).

Pero las invenciones en las jams demuestran que las alternativas a los controlatorios exceden las mutaciones en las líneas molares del agenciamiento videojuegos (como los reparos en los elementos representacionales o temáticos), pues existen formas más complejas de afectar la máquina abstracta del poder contemporáneo. De hecho, Deleuze y Guattari tendrán una mirada ambivalente sobre los agenciamientos massmediáticos e informacionales, suponiéndolos partes fundamentales del capitalismo contemporáneo pero también vías de experimentación que, al trabajar en el nuevo régimen de las imágenes, permiten crear un arte del control (Rossi, 2018a). Esta resistencia trazaría un continuum de intensidades (afectos y perceptos) en procesos de devenir que llevan al límite las máquinas deseantes a través de la creación (cuerpo sin órganos). Brevemente, se puede decir que en el caso del videojuego como vector desterritorializante ir contra el mainstream es un gesto inmediatamente político, porque se trata del cognitariado en formación el que se impone vías de experimentación en el corazón de la axiomática capitalista.

Si bien los autores piensan en el cine, en la música electrónica o en la literatura, para nosotros la idea de un arte del control sobrevive en las indagaciones de la gameplay por parte de las/os desarrolladoras/es. Pues si el video ha sido un instrumento para aumentar las altas velocidades y controlarlas (un controlatorio), algunos juegos de la GGJ buscan extraer de las semióticas intensivas puras líneas de lentitud. Los ejemplos surgen de juegos donde las dinámicas favorecen un detenimiento permanente que opaca las configuraciones de combate y arenas (1) o donde mecánicas inusuales (8) entran en alianza con la poética para quebrar las vías de racionalización del capitalismo contemporáneo (Pedercini, 2014). También hay experimentaciones $(27,28)$ que buscan desprender intensidades de la colaboración en la lentitud contra la soledad maquínica (que aterraba a Guattari y a V. Flusser) y juegos que desprenden intensidades del sistema cara-paisaje (31) rompiendo la función individualizadora y socializadora del rostro o Rostridad (Rossi, 2018a).Todas estas vacuolas de no comunicación están ligadas a modos de subjetivación maquínica que se corresponden con lo que Guattari denominaba era post-mediática como prácticas sociales y estéticas innovadoras que implican campos creativos de percepción y de afección en procesos estéticos que hacen arte más allá del arte. 
Asimismo, las GGJ empujan a los desarrolladores a devenires minoritarios ya que cuando el cognitariado experimenta con juegos abre bloques de devenir (o fugas) que van a contramano de la infantilización de la industria global sobre las líneas molares (e.g. Kawaii). Hay un devenir-niño complejo en los videojuegos como agenciamientos que se compone de afectos y perceptos que son arrancados de las imágenes y que, como quiere Cremin, incluyen un jugar rizomático que forja espacios lisos en las estriaciones del código arborescente. Este movimiento incorpora un tratamiento jovial de los glitches en la mayoría de los proyectos de la GGJ, lo que va a contramano de la creencia en una comunicación sin fallas y abre una poiesis frente al control informático. Asimismo, este devenir es legible en exploraciones de diseños intencionalmente abusivos o aberrantes (Sicart y Wilson, 2010) que desafían las convenciones y evitan ser divertimentos pasatistas $(35,36)$. En particular, algunos desarrollos (37) tienen niveles y contenidos de impossible game que emulan un espacio liso y promueven un impersonal variable en tercera persona ("se juega") que parece actualizar la máquina de guerra del go (Deleuze y Guattari, 1997).

Concomitantemente al devenir-niño hay otro proceso minoritario que arrastra a las/os desarrolladoras/es. Para Deleuze y Guattari las nuevas formas del capitalismo dotaban al cognitariado de una fuerza de imprevisibilidad (Rossi, 2018a) "proporcionan[do] otras tantas armas al devenir de todo el mundo, devenir-radio, devenir-electrónica, devenir-molecular" (Deleuze y Guattari, 1997: 476). Para nosotros la idea de devenir-electrónica cifra una fuga molecular que puede ser pensada en conjunto con la noción de epifanía de las técnicas que G. Simondon recuperaba observando el jugar tecnológico (Rossi, 2018b) y que algunos autores como S. Giddings han advertido respecto de los videojuegos. Se trata de un jugar tecnológico que gesta una participación activa de comprensión intuitiva o connaturalidad fraternal que rompe la actitud de defensa de la cultura frente a las técnicas. Jóvenes, jugadoras/es e inventoras/es parecen configurar exactamente el reverso del cognitariado en las GGJ, por ello no es extraño que ese devenir-electrónica se muestre en algunos juegos que intentan sistemáticamente explorar el hardware para emular sensaciones inusitadas $(32,33)$. En algunos casos, los sensores (34) buscan emular derivas esquizoides al tiempo que el jugador es arrastrado a descubrir el input adecuado (open hardware). En esas epifanías de las técnicas se confirma la idea guattariana de ver a las/os jugadoras/es o desarrolladoras/es como los locos de las máquinas que pueden percibir lo imperceptible y que encuentran en las realidades técnicas y sus semióticas a-significantes la manera de liberar el potencial esquizo de las máquinas deseantes.

De hecho, para Deleuze y Guattari, las semióticas a-significantes señalaban fuerzas desestratificantes y desterritorializantes que entraban en relación con la noción de dividual como relación entre la obra de arte y los seres que luchan (o el pueblo que falta). Las máquinas deseantes puestas en funcionamiento por los videojuegos como agenciamientos guardan vías estéticas de creación de nuevos modos de subjetivación (o micro-política), al tiempo que las jams se presentan como modos de experimentación que encierran intentos de las/os desarrolladoras/es por alcanzar un pensar futuro que busca ser juego abierto. Un pensamiento que no es un estéril ejercicio de una facultad, sino una fuerza del Afuera y que promete crear nuevas formas de vida con la prudencia suficiente para liberar máquinas deseantes sin que se conviertan en pura y simple destrucción. 


\section{Notas}

1. El término imágenes en sentido simondoniano implica dimensiones visuales, sonoras y táctiles.

2. Para una caracterización de las GGJ ver Rossi (2019).

3. Los juegos analizados serán numerados (del 1 al 45).

4. Las grillas recabaron información sobre las líneas mencionadas y fueron complementadas con técnicas observacionales durante las GGJ (Rossi, 2019).

\section{Referencias bibliográficas}

Apperley, T. (2011). Gaming rhythms. Amsterdam: Institute of Network Cultures.

Bogost, I. (2006). Unit Operations. Cambridge: MIT Press.

Collins, K. (2013). Playing with sound. Cambridge: MIT Press.

Cremin, C. (2016). Exploring Videogames with Deleuze and Guattari. New York: Routledge.

Deleuze, G. (2008). Dos regímenes de Locos. Valencia: Pre-Textos.

Deleuze, G. y Guattari, F. (1997). Mil Mesetas. Valencia: Pre-Textos.

Dovey, J. y Kennedy, H. (2006). Games Cultures. Glasgow: Open University Press.

Dyer-Witheford, N. y de Peuter, G. (2009). Games of Empire. Minneapolis: UMP.

Eskelinen, M. (2012) Cybertext poetics. Londres: Bloomsbury Publishing.

Friedman, T. (2002). Civilization and Its Discontents. Smith, G. (Ed). On a Silver Platter. 132-150. New York: NUP.

Galloway, A. (2006). Gaming. Minneapolis:UMP.

Gazzard, A. (2009). Paths, players, places (tesis doctoral). University of Hertfordshire, Gran Bretaña.

Guevara-Villalobos, O. (2013). Cultural production and politics of the digital games industry (tesis doctoral). University of Edinburgh, Escocia.

Järvinen, A. (2008). Games Without Frontiers (tesis doctoral). Tampere University, Finlandia. Meldgaard, B. (2011). Dangerous Forms (tesis doctoral). Aalborg University, Dinamarca.

Newman, J. (2004). Videogames. Londres: Routledge.

Nitsche, M. (2008). Video Game Spaces. Cambridge: MIT Press.

Papadopoulos, S. (2011). Urban landscapes in video games. Grecia, URL: http://www.arch. uth.gr/urbanlandscapesinvideogames.

Pedercini, P. (2014). Videogames and The Spirit of Capitalism (mensaje en blog). Molleindustria. Recuperado de http://www.molleindustria.org/blog/videogames-and-the-spiritof-capitalism/

Rossi, L. (2018a). Agenciamientos en las sociedades de control. CUHSO, 28(1), 177-206.

Rossi, L. (2018b). El modo de existencia de las imágenes a la luz de Simondon. Reflexiones Marginales, (48). Recuperado de: https://2018.reflexionesmarginales.com/el-modo-deexistencia-de-las-imagenes-a-la-luz-de-simondon/

Rossi, L. (2018c). Apuntes sobre algunas relaciones históricas entre juego y máquinas. Lúdicamente, $4(1)$. 
Rossi, L. (2019).Videojuegos y sociedades de control: la formación del cognitariado en las Global Game Jams. Revista Crítica de Ciências Sociais, (118), 101-124.

Walz, S. (2010). Toward a Ludic Architecture. Pittsburgh: ETC Press.

\section{Videojuegos de la Global Game Jam de 2010 a 2016.}

Recuperados de: https://globalgamejam.org/games

1. Deathception (2010)

2. Land the Mime (2010)

3. Board Extintion (2011)

4. Dino Slayer (2011)

5. Downgrade Complete (2011)

6. Extíngueme si puedes (2011)

7. Kill the ligths (2011)

8. Missing (2011)

9. The Entity (2011)

10. Virus Lothar (2011)

11. Apocalipsis (2012)

12. Banvet (2012)

13. Chicken Defense (2012)

14. ValleOuroboros (2012)

15. Elusive Spirit (2012)

16. Panic Snake (2012)

17. Spider Loop (2012)

18. Todajato (2012)

19. Taquicardia (2013)

20. Marcos Paso (2013)

21. Destaparterias (2013)

22. Insane Heart(2013)

23. Sheep Master (2013)

24. SuperPipeHeart (2013)

25. Doki Doki (2013)

26. ClarOscuro (2014)

27. L’Empire de la Mort (2014)

28. Monochrome (2014)

29. Safari Race (2014)

30. Schrödinger's Maze (2014)

31. Egocentric (2014)

32. Sigilo (2014)

33. Batch Desesperation (2015)

34. Dolores (2015)

35. Jimmy, el chabón (2015) 
36. Physikaos (2015)

37. Square Revenge (2015)

38. Traptest (2015)

39. The Dungeon of the lost children (2015)

40. Ritual Blood (2016)

41. Voodoo Cloud (2016)

42. The Ritual of Namaka (2016)

43. Timmy don't sleep (2016)

44. Hellffort (2016)

45. Argieman Origins (2016)

\begin{abstract}
Recently several studies have explored the limits and possibilities of videogames as expression of globalized cultural industry but also as a resistance point to capitalism. However, these conceptualizations often omit fundamental features of videogames as apparatuses (dispositifs) or assemblages (agencements) of contemporary societies as well as their relations with modes of subjectification forged in engagement (refrain). Our proposal will recover the elements that allow videogames to be studied as condensation of sign regimes (images) and materialities by identifying the lines (molecular, molar and abstract) that compose ( $r e$ / territorialize) digital video game assemblages (intensive semiotics of spatiality, mechanics and gameplay), as well as their possible lines of flight (deterritorialization). Likewise, if our analytical model finds its theoretical foundations in French post-structuralism, this paper will rely on the main contributions of applied ludology. Therefore, our paper will present a empirical analysis (comparative grids) on a corpus of 45 developments produced between 2010 and 2016 in Global Game Jams of the city of Santa Fe.
\end{abstract}

Keywords: sign regimes - materialities - game/play assemblages - Global Game Jams - engagement - applied ludology.

Resumo: Nos últimos anos, vários estudos abordaram os limites e as possibilidades dos video games como uma verdadeira expressão da indústria cultural globalizada, mas também como uma fronteira resistente ao capitalismo. Contudo, essas construções teóricas geralmente omitem as características fundamentais dos video games como dispositivos ou agenciamientos das sociedades contemporâneas, bem como suas relações com os modos de subjetivação forjados no engagement (ritornelo). Nossa proposta buscará recuperar os elementos que permitem que os video games sejam vistos como condensação de regimes de signos (imagens) e materialidades, identificando as linhas (moleculares, molares e abstratas) que compõem (re/territorializam) as agenciamientos de jogos digitais (espacialidade, mecânica e gameplay), bem como suas possíveis linhas de fuga (desterritorialização). Além disso, se o modelo analítico encontre seus fundamentos 
teóricos no pós-estruturalismo francês, a pesquisa contará com as principais contribuições da ludologia aplicada. Portanto nosso artigo será baseado em experiências (quadros comparativos) em um corpus de 45 video games produzidos entre 2010 e 2016 nas Global Game Jams da cidade de Santa Fe.

Palavras chave: regimes de signos - materialidades - agenciamiento de jogos - Global Game Jams - engagement - ludologia aplicada.

[Las traducciones de los abstracts fueron supervisadas por el autor de cada artículo] 


\section{De Tolkien al LitRPG: MMORPGS y transmediación}

Martín M. Vizzotti ${ }^{(1)}$

Resumen: En este artículo recorremos un derrotero transmediático que tiene como resultado el surgimiento de un nuevo género literario, el LitRPG (Literary RPG). Este proceso comienza en la década del 70 cuando se interactivizan ciertas literaturas y autores eminentes como Tolkien, Lovecraft, Moorcock, Howard et al. y aparecen los primeros RPG (Role Playing Games), luego, estos son transmediados a los nuevos soportes cibernéticos para dar origen a los CRPG (Computer RPG), MUDs (Multi User Domain/ Dungeon) y finalmente los MMORPG (Massive Multiplayer Online RPG), cuyas lógicas y características discursivas irrumpen en el terreno literario a través de las obras de LitRPG y generan un regreso a la literatura a partir de un proceso de desinteractivación.

Además de analizar el proceso de transmediación, se analizan también las características principales de este nuevo género, adentrándonos en la obra de cuatro autores considerados pioneros: D. Rus, G. Akella, V. Mahanenko y Yu Wo, así como también en ciertas características prefiguradas en ciertos precursores del género (en términos de "Kafka y sus precursores", de J. L. Borges).

Palabras clave: LitRPG - D. Rus - G. Akella - V. Mahanenko - Yu Wo - Transmediación - RPG - MMORPG

[Resúmenes en inglés y portugués en las páginas 157-158]

(1) Profesor, Licenciado y Doctor en Letras de la Facultad de Humanidades y Ciencias de la Educación de la Universidad Nacional de La Plata. Es docente en el Área de Latín desde el año 2000 y Profesor Adjunto ordinario en el área desde 2015. Ha dictado numerosos seminarios de grado y posgrado y publicado artículos en revistas Nacionales e Internacionales. 